\title{
Experiences of incontinence and pelvic floor muscle training after gynaecologic cancer treatment
}

\author{
Anna Lindgren $^{1}$ (D) G. Dunberger ${ }^{2}$ - A. Enblom ${ }^{1,3}$ \\ Received: 7 January 2016 / Accepted: 23 August 2016/Published online: 5 September 2016 \\ (C) The Author(s) 2016. This article is published with open access at Springerlink.com
}

\begin{abstract}
Purpose The purpose of the present study is to describe how gynaecological cancer survivors (GCS) experience incontinence in relation to quality of life, their possibilities for physical activity and exercise and their perceptions and experiences of pelvic floor muscle training.

Method This qualitative interview content analysis study included 13 women (48-82 age) with urinary $(n=10)$ or faecal $(n=3)$ incontinence after radiation therapy $(n=2)$, surgery $(n=5)$ and surgery and radiation therapy $(n=6)$ for gynaecological cancer, $0.5-21$ years ago.

Result Symptoms related to incontinence and restrictions in daily activities reduced physical quality of life. Emotions related to incontinence reduced psychological quality of life and social and existential quality of life, due to restrictions in activity and feelings of exclusion. Practical and mental strategies for maintaining quality of life were described, such as always bringing a change of clothes and accepting the situation. Possibilities for sexual and physical activity as well as exercise were also restricted by incontinence. The women had little or no experience of pelvic floor muscle training but have a positive attitude towards trying it. They also described a lack of information about the risk of incontinence. The women were willing to spend both money and time on an effective
\end{abstract}

Anna Lindgren

anna.lindgren@liu.se

1 Division of Physiotherapy, Department of Medical and Health Sciences, Linköping University, 58183 Linköping, Sweden

2 Department of Health Care Sciences, Ersta Sköndal University College, Stockholm, Sweden

3 Department of Clinical Neuroscience, Karolinska Institute, Osher Centre for Integrative Medicine, Stockholm, Sweden treatment for their incontinence. Nine out of 10 were willing to spend at least $7 \mathrm{~h}$ a week.

Conclusion GCS experienced that incontinence reduced quality of life and limited possibilities for sexual and physical activity as well as exercise. Coping strategies, both practical and emotional, facilitated living with incontinence. The women had a positive attitude towards pelvic floor muscle training. Lack of information had a negative impact on their way of dealing with the situation.

Keywords Incontinence - Gynaecologic cancer - Quality of life · Pelvic floor muscle training · Physical activity ·

Physiotherapy

\section{Introduction}

Gynaecological cancer treatment continues to improve, resulting in an increased number of cancer survivors [1]. However, they risk long-term-treatment-related side effects in the pelvic region [2-4]. In Sweden, more than 30,000 women are gynaecological cancer survivors (GCS) [5].

Incontinence, from either the urinary tract or the anal sphincter [3], is a common and burdensome side effect of gynaecological cancer treatment $[2,3]$. In a study of late side effects in GCS, one third of the women reported urinary leakage, which makes the risk of urinary leakage $75 \%$ higher in GCS compared to women in general [2]. In another study, $12 \%$ of the GCS reported leakage of all faeces without warning, which compares to $1 \%$ in control women [3]. Incontinence is defined by the International Incontinence Society (ICS) as involuntary loss of urine or faecal material $[6,7]$.

GCS with faecal incontinence also reported a reduced quality of life (QoL) compared to control women [2, 3]. Faecal 
incontinence was also seen to lower the level of physical activity, in both sexual and everyday activities [3]. Also, urinary incontinence tends to lower QoL in everyday physical activities [8]. All these findings were made in quantitative studies [2, 3, 8-11]. However, knowledge on a deeper level is lacking.

Generally, pelvic floor muscle training (PFMT) is recommended as an effective first-line treatment for urinary and faecal incontinence $[12,13]$ that may increase ability to physical activity [9] and improved QoL [12]. However, the effect of PFMT after gynaecological cancer treatment is not known [14]; nor are the health economic perspectives [15]. It is also not known what experiences, perceptions and thoughts that GCS have of PFMT.

The purpose of this study is thus to describe how GCS experience incontinence in relation to perceived QoL, opportunities for physical activity and exercise and how they perceive and experience PFMT. Unless otherwise stated, both urinary and faecal leakage is referred to as incontinence.

\section{Participants and methods}

\section{Design}

This qualitative descriptive interview study [16] was performed to generate a deeper understanding of GCS's experiences of incontinence and PFMT. The data was collected through interviews using a semistructured interview guide and was analysed with content analysis [17]. The Regional Ethical Review Board approved the study.

\section{Participants}

Thirteen participants were recruited: ten from a patient association for GCS and three through a Swedish oncology rehabilitation reception for side effects. A letter with information about the study was provided, and interested women were encouraged to send contact information for further verbal information about the study. Those who met the study criteria and provided written informed consent were enrolled and interviewed until the content from the interviews was assessed as rich ( $n=13$ study participants: $\mathrm{R} 1-\mathrm{R} 13)$.

The inclusion criteria was as follows: women aged $\geq 18$ years; had received treatment for gynaecological cancer; had undergone subsequent verification after completion of treatment; had urinary and/or faecal incontinence according to ICS definition of incontinence [7]; able to read, talk and understand Swedish; and able to move indoors without aids. Exclusion criteria were ongoing cancer or previously conducted or planned surgery against incontinence.

A written study-specific valid questionnaire [4, 18] collected demographic- and treatment-related information at the start of the interview. The median age was 66 years (range 48-82) and duration since cancer treatment median 3.5 years (range 0.5-21). Five of the women had undergone surgery, two had merely received radiotherapy, and six had surgery and radiotherapy (Table 1).

\section{Data collection}

To examine how GCS perceive the value of a treatment that could reduce incontinence, the written study-specific questionnaire also included four questions (seen in Table 3), formulated according to established methods used in cost-utility studies [15].

The first author (AL) conducted individual digital-recorded interviews. The participants selected the location for the interview. The interviewer used a semistructured interview guide with open-ended questions formulated by the authors based on the study purpose (Appendix). It started with: "Can you tell us how incontinence affects your life in general, for example, related to what is usually called quality of life?" The interviewer gave no predetermined definition of "quality of life", "physical activity" and "pelvic floor muscle training" during the interview, leaving the respondents to describe how they perceived the concepts. The interviewer tested the guide in two interviews and made minor clarifying corrections. For instance, "problems with incontinence" was changed to "incontinence", so as not to point out incontinence as being a problem. The interviews lasted 25-54 min (median $37 \mathrm{~min}$ ).

\section{Data analysis}

The first author (AL) transcribed the interviews verbatim and performed a qualitative content analysis [17] in collaboration with the last author (AE). To create a sense of the whole and to pick out phrases and sentences with information relevant to the purpose of the study, socalled meaningful units, the text was read several times (AL, AE). The approach was to not select units that were too long, as they could contain more than one phenomenon, nor too short because of the risk that the material may become fragmented [17]. AL condensed the meaningful units to compress the text without losing its content and coded the condensed meaningful units. AL and AE, first independently of each other, placed the condensed meaningful units into groups representing different categories. Categories were discussed until a consensus was reached that the categories reflected the central message of the interviews in light of the purpose of the study. Each meaningful unit belonged to a relevant category and never to more than one category [17]. As a validation of the analysis, the second author (GD) read the analysis and confirmed that it was valid in light of the content in the transcripts. 
Support Care Cancer (2017) 25:157-166

159

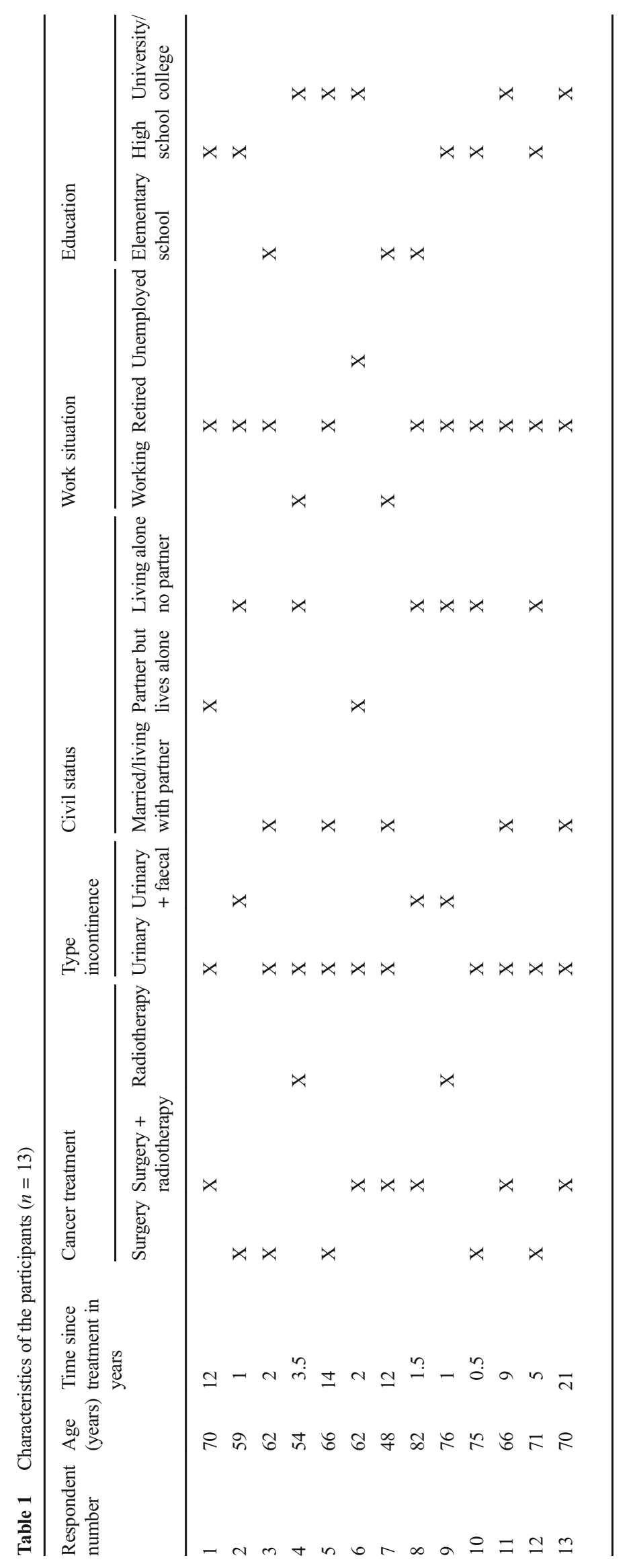

Springer 


\section{Results}

The analysis resulted in three categories and 13 subcategories (Table 2).

\section{Category 1: emotional reactions, thoughts and musings that incontinence contributes to}

The women talked about their QoL in relation to feelings, thoughts and reflections that incontinence contributes to, such as anxiety, fear, lack of freedom and a sense of alienation.

\section{Worry and fear of leakage}

The women described how the risk of involuntary leakage in different contexts creates anxiety and fear. Their concerns include not being close enough to a toilet when outside their home. They also fear that involuntary leakage will be noticed by others, due to stains on their clothes or an unpleasant odour. This would, in turn, cause a sense of shame.

I never know when it comes, and when it comes I must have a toilet, that's a concern. (R2).

\section{Feelings of exclusion and not fitting in}

The women related their QoL to existential musings. They described how incontinence can lead to an experience of alienation and not fitting in. This exclusion was caused by the feeling different from everyone else. The women also described feelings of not being good enough and said that their surroundings can be unaware how much trouble that they are going through. Realising that they are not alone in suffering from incontinence was described as a relief.

...it was such a relief, it's not just me that's wrong. (R2)

\section{Feelings of lack of freedom in everyday life}

They described how incontinence feels like a handicap in their daily life and that it causes feelings of limitation and a lack of freedom. For example, they described the experience of not being able to be spontaneous in the same way as before.

Well, it has changed a bit because I don't feel as free as I used to. (R8)

\section{Gratitude to be alive and not to be the worst affected}

While the women do consider incontinence to be a big problem, they also feel grateful to be alive and cancer free. Furthermore, the experience of not being the worst stricken, in terms of the severity of the side effects, was described as a sense of relief.

Well, I could just as well have been dead. But we should not trivialise it, because it's really hard, after all. (R4)
Table 2 Categories and subcategories describing GCS' experiences of incontinence in relation to perceived QoL, opportunities for physical activity and exercise and their perceptions and experiences of pelvic floor muscle training

\begin{tabular}{ll}
\hline Category & Subcategory \\
\hline $\begin{array}{l}\text { Emotional reactions, thoughts and musings that } \\
\text { incontinence contribute to }\end{array}$ & - Worry and fear of leakage \\
& - Feelings of exclusion and not fitting \\
& - Feelings of lack of freedom in everyday life \\
& - Gratitude to be alive and not to be the worst affected \\
Adaption and strategies to maintain a good quality & - Practical adaptation to avoid leakage or that leakage is \\
of life & noted by the environment \\
& - Acceptance of their situation \\
& - Tell others about incontinence \\
& - Own responsibility to maintain a good quality of life \\
Activity, pelvic floor muscle training and & - To be active in daily life \\
information & - Consequences of physical inactivity \\
& - Experiences of pelvic floor muscle training \\
& - Beliefs about pelvic floor muscle training \\
& - Desires about pelvic floor muscle training \\
& - Lack of information about incontinence and pelvic floor \\
& muscle training
\end{tabular}

Categories and subcategories presented, representing the meaningful units of the content of the central message of the interviews 


\section{Category 2: adaption and strategies to maintain a good QoL}

The women related their QoL to the bothersome symptoms of incontinence, as well as the need for adaptation in everyday life. They described their experiences of different strategies used to maintain their QoL and reduce the impact of incontinence in daily life. A variety of approaches were mentioned.

\section{Practical adaptation to avoid leakage or that leakage is noted by the environment}

The women described practical measures taken in order to always be prepared in case of a leakage, such as bringing extra clothes and incontinence aids during activities at both daytime and nighttime. They also said that it was necessary to know the location of the toilets when participating in activities outside the home.

I prepare everything for it to work, and I have change of clothes with me if it would go so badly. (R3)

In order to reduce the risk of incontinence, the women described the necessity to consider what, when and how much to eat and drink depending on the planned activity. For instance, avoiding spicy food or bread with whole grains was said to be a way of preventing faecal leakage, while not drinking the hours before physical activity was described as a way to reduce the risk of urinary leakage.

If I know I'm going somewhere I don't drink a lot before. (R1)

They also said that the ingestion of drugs can relieve symptoms of faecal incontinence and facilitate life outside the home. Another strategy is to perform activities in proximity of a toilet and a shower and where a change of clothes is available. They also said that they feel that it is safer to perform physically strenuous activities at home, compared to outside the home, since this makes it less likely that a leakage of faeces or urine will be noted by strangers.

If I'm at home and do my chores I'm always close to the toilet and can make it in time, and if an accident happens, I have the opportunity to wash myself or take a shower. (R3)

\section{Acceptance of their situation}

Respondents described how they gradually learned to accept the situation. Furthermore, they said that the lack of a choice makes it possible to live with incontinence. The women try to live as normally as possible and avoid making the situation more problematic than it is. They feel that they can live a relatively normal life by accepting the situation.

If you're in the situation, you'll adapt to it, that's just the way it is. (R1)

\section{Tell others about incontinence}

The women said that it can be difficult to tell friends and relatives that they suffer from incontinence. At the same time, they said that it is easier to be open about their incontinence to relatives compared to strangers. Talking about their problems was also described as a way to make others understand their situation and avoid misunderstandings, as well as unpleasant and embarrassing situations. Being more open and talking about incontinence were described as important since it was believed that an increased knowledge can lead to more openness. They said that when they had told people about their incontinence, others around them had experienced it as a relief and had dared to talk about their own problems with incontinence.

They know about it and I think that's great... if you say you don't wish to attend... if you know you'll not be able to get to a toilet in a long time, then they know why you say so. It's not because I don't want to be with them. (R3)

\section{Own responsibility to maintain a good $Q o L$}

Respondents described the importance of personal responsibility to demolish the obstacles that they experience and to not let incontinence keep them from doing things that they want to do. Some said that they, alone, can change their situation for the better.

It's only me that can change; there's no one else that can change. (R1)

\section{Category 3: activity, PFMT and information}

\section{To be active in daily life}

Feelings of limitation were described when it comes to everyday chores like shopping, gardening and running errands. The women said that they do not dare to participate in social activities, such as dancing, travelling or going out for dinner with friends. 
When I was meant to meet my former workmates in town, I didn't dare to go there. (R9)

They also said that they are experiencing difficulties when it comes to being sexually active. Some women described a concern about initiating new sexual relationships because of fear of leakage. They described the importance of getting to know a new person and to build up a considerable trust in this person before a sexual relationship is started. Casual sexual relationships were described by some women as unthinkable. Even women that were in a stable relationship described a concern for leakage in the sexual context, but several of them described, at the same time, that their partners showed great understanding and did not see a possible leakage as a major problem. Some of the women said that they were sexually inactive because their partner had passed away. They were no longer interested in having sexual relations, but they probably would have felt limited sexually if they had been younger or if their partner had been alive.

... I'm single, and nowadays I would not just hook up with somebody and go to bed and say hey I'll just take my diaper of first, one would not expose oneself to such a situation. (R4)

They also described how good planning allows them to be active in social settings. The women said that they can take daily walks but often not as far as before. With good planning and the possibility of multiple breaks, they can perform physical exercises such as water aerobics. However, they also said that they are no longer engaged in various forms of physical exercise, such as running, cycling, horse riding, gymnastics and swimming.

Yes, both to bike and ride are two things I can't do anymore, and it's a little sad, of course. And then, like running or going on group training, it's no longer for me. (R4)

Physical exercise in a group was said to be difficult to take part in, and some had stopped performing activities for this reason. At the same time, others said that they are still able to carry out physical exercise in a group under the premise that a toilet is nearby.

\section{Consequences of physical inactivity}

The decrease in activity caused by incontinence was said to cause weight gain and stiffness, as well as a decrease in energy, physical fitness and their desire to be physically active.

Not being able to perform physical exercise has a negative effect of the body...you become numb, you get tired and everything. It's really important

to keep moving. (R5)

\section{Experiences of PFMT}

Some women said that they had practiced PFMT after cancer treatment on their own initiative, despite never having been told to do so during or after treatment. Some women described PFMT as difficult; others said that it was not so difficult. Some women felt that PFMT had a positive effect on urinary incontinence. Meanwhile, others had a more hesitant attitude towards the effect.

I'm fully convinced that I can influence the pelvic floor muscles, although they are a bit damaged. (R4)

It's a bit tough, I think, difficult. I don't know if I'm doing it right. (R6)

\section{Beliefs about PFMT}

Most women thought that PFMT would prove to be beneficial and not very difficult, and some thought that it might hurt. They also had a positive attitude towards PFMT, granted that it could reduce incontinence.

I think it would be really good, I mean it [the incontinence] has not improved with age either. (R7)

\section{Desires about PFMT}

The women described the importance of being instructed by someone that is familiar with PFMT and knows how to do it. They also said that it is important that they felt confident in the ability of their instructor. They described the desire to participate in a PFMT group and to have a written training program to carry out at home after a thorough instruction by a physiotherapist. They also described their experience of not being offered physical therapy after gynaecological cancer treatment.

First, individual training or information a number of times and then in a group. (R3)

\section{Lack of information about incontinence and PFMT}

They said that they had not received any information about incontinence as a possible side effect of gynaecological cancer and that no one had mentioned PFMT during or after 
completion of treatment. Some thought that if they had been informed of PFMT as a possible strategy to alleviate incontinence, they might not have had as much trouble with incontinence. Lack of information also contributed to the belief that they were alone in their situation and to unrealistic expectations of treatment, as they were unaware of potential side effects.

\section{The value of an effective treatment for incontinence}

Seven out of 11 participants said that an effective treatment for their incontinence would have a value of 100,000 SEK (ca. 10,518 Euro or 11,575 US dollars; http://www.valuta.se/ date July 29, 2016). This value is comparable with 4-month salary in Sweden (mean gross income 4 months, 100,535 SEK/10 ,575 Euro/11,637 US dollars, Statistics Sweden; http://www. scb.se/ date July 29, 2016). Nine women said that they were willing to spend at least $7 \mathrm{~h}$ per week on such a treatment (Table 3).

\section{Discussion}

In summary, GCS describe in-depth how incontinence of urine or faeces compromises their perceived QoL in all of the dimensions that WHO names as physical, psychological, social and existential QoL [19]. The cancer survivors described various strategies to maintain QoL. They also said that incontinence limits their possibilities for physical activity and exercise. The women had little or no experience of PFMT but expressed a positive attitude towards it and a will to take part in it, preferably with a physiotherapist, if it could lead to decreased incontinence. The women also said that there had been an absence of information about incontinence as a possible side effect of gynaecological cancer treatment, as well as what its consequences and possible treatment options are. This negatively affected their way of coping with the condition.

In line with our study, participants in an epidemiology study ( $n=9487$ ) reported that urinary incontinence affected QoL negatively in all dimensions mentioned, as the fear of not reaching a toilet in time caused them to avoid social activities, physical exercise, etc. [8]. In another study of GCS with urinary incontinence, the most affected QoL factor was mental well-being [20]. GCS with faecal incontinence have described a reduction in QoL since incontinence keeps them from social activities, hinders their sexual activity and forces them to always locate accessible toilets in advance. In our study, several women described casual sexual relationships as unthinkable and even women who lived in a stable relationship described a concern for leakage in the sexual context. This gives a deeper understanding to the previous observation that $25 \%$ of 64 GCS experiencing faecal leakage without forewarning stated

Table 3 Gynaecological cancer survivors' own perceptions of the value of a treatment that could reduce incontinence

\begin{tabular}{lllll}
\hline $\begin{array}{l}\text { Respondent } \\
\text { number }\end{array}$ & $\begin{array}{l}\text { 1. How much are you willing } \\
\text { to pay for a treatment that } \\
\text { would lead to complete } \\
\text { recovery from incontinence? } \\
\text { (SEK/Euro/US dollars) }\end{array}$ & $\begin{array}{l}\text { 2. How much are you willing to } \\
\text { pay for a treatment that would lead } \\
\text { to recovery to the point that } \\
\text { incontinence does not affect your } \\
\text { daily life? (SEK/Euro/US dollars) }\end{array}$ & $\begin{array}{l}\text { 3. How much time are you } \\
\text { willing to spend on a } \\
\text { treatment that would lead to } \\
\text { complete recovery from } \\
\text { incontinence? (h per week) }\end{array}$ & $\begin{array}{l}\text { 4. How much time are you willing } \\
\text { to spend on a treatment that would } \\
\text { incontinence does not affect your } \\
\text { daily life? (h per week) }\end{array}$ \\
\hline 1 & $3000 / 314 / 348$ & $3000 / 314 / 348$ & 3.5 & 3.5 \\
2 & $150,000 / 15,691 / 17,407$ & $50,000 / 5230 / 5802$ & All time needed & All time needed \\
3 & $10,000 / 1046 / 1160$ & $10,000 / 1046 / 1160$ & All time needed & All time needed \\
$4^{\text {a }}$ & - & - & - & - \\
5 & $150,000 / 15,691 / 17,407$ & $50,000 / 5230 / 5802$ & All time needed & All time needed \\
6 & $100,000 / 10,461 / 11,605$ & $100,000 / 10,461 / 11,605$ & $7-14$ & $2-3$ \\
7 & 2000 & 2000 & 1 year & 1 year \\
8 & $1,000,000 / 104,609 / 116,046$ & $1,000,000 / 104,609 / 116,046$ & 4 & 4 \\
9 & $1,000,000 / 104,609 / 116,046$ & $1,000,000 / 104,609 / 116,046$ & All time needed & All time needed \\
$10^{\text {a }}$ & - & - & All time needed & All time needed \\
11 & Priceless & Priceless & All time needed & All time needed \\
12 & $10,000 / 1046 / 1160$ & $10,000 / 1046 / 1160$ & All time needed & All time needed \\
13 & $500,000 / 52,305 / 58,023$ & $500,000 / 52,305 / 58,023$ & $2-3$ & $2-3$
\end{tabular}

$1 \mathrm{SEK}=0.10$ Euro or 0.12 US dollars (http://www.valuta.se/ date July 29, 2016). The figures may be related to the fact that the mean gross income per month in the country for the study was 25,134 SEK/2629 Euros/2917 US dollars. The women were informed that the willingness to pay was hypothetical, according to established economic evaluation methods [15]

SEK Swedish crowns

${ }^{a}$ One of the 13 participating women did not answer questions $1-4$, and one did not answer questions $1-2$; they gave no reason 
that leakage has hindered their sexual activity, compared to $3 \%$ of 524 women without faecal leakage without forewarning [21]. It is important to consider GCS's QoL from several different dimensions since QoL is a subjective experience that must accommodate all aspects of a person's life situation [22]. Corresponding results have been presented in a study among Swedish women with incontinence that are not GCS [23].

The way that the GCS used various strategies to maintaining QoL may be related to the concept of coping, previously described by Anders. Women in general with urinary incontinence emphasised that coping strategies play an important role in managing incontinence [24]. We have not found any previous studies reporting on coping strategies used by GCS to manage incontinence.

The finding that incontinence limits the survivors' possibilities for physical activity and exercise is in line with Andersson et al. and their findings on women with urinary incontinence [23]. A reduced level of everyday physical activity and exercise is one of the most commonly reported lifestyle changes in women with incontinence [3, 8, 24]. Physical activity may contribute to improving QoL and lowering the risk of recurrence of cancer and premature death, while inactivity is a risk factor for a range of diseases.

In a pilot study, the adherence to PFMT combined with behavioural therapy was high, and this intervention improved GCS's urinary incontinence compared to no exercise [14]. Still, we lack satisfactory randomised controlled studies of effectiveness as well as costs. Thus, we study pilot tested a question regarding "willingness to pay" [15] for PFMT, and the answers indicate the value of further studying PFMT in GCS. Our sample is very small, so the exact figures are not relevant. However, it is interesting that almost all participants said that they were willing to spend at least $7 \mathrm{~h}$ per week on PFMT and seven out of 11 women said that an effective treatment for incontinence has a value comparable with almost 4-month salary, according to the mean gross income level in the country for the study (Statistics Sweden; www.scb.se, date July 29, 2016). The women would be prepared to spend time and money on PFMT. The GCS's individual answers and methodology papers regarding the validity of willingness-to-pay values in relation to ranking of intervention alternatives [25] provide knowledge on how to formulate structured answering alternatives in future costbenefit evaluations of PFMT.

An interesting finding from an ethical perspective is that the women said that there had been an absence of information. It is indefensible that patients receiving any cancer treatment should not get information about potential side effects, especially disabling symptoms such as incontinence. Calman et al. describes the lowering of QoL in cancer survivors as the gap or difference between earlier goals, hopes and expectations and how they actually experience their current life situation [26]. Increased awareness among gynaecological cancer patients that incontinence is a potential side effect of treatment [2,3] may potentially spare them unnecessary suffering.

As a methodology reflection, the content was assessed as rich and as reflecting the respondents' views on living with incontinence after cancer treatment. Within the last interviews, we noticed that the women reported experiences similar to those in previous interviews. Compared to previous quantitative studies [2,3,8-11], our study brings knowledge on a deeper level. We chose individual interviews [16] for data collection since we wanted a deeper understanding of the intimate problem of incontinence and content analysis was considered the most preferable analysis method: even if it cannot be generalised [17]. The validity of our analysis was secured [27] by two analysers and validated by a third.

In conclusion, GCS experienced that incontinence leads to a reduced QoL and limits their possibilities for physical activity and exercise. Coping strategies, both practical and emotional, are used to facilitate living with incontinence. The women have a positive attitude towards PFMT. Lack of information has a negative impact on their way of dealing with the situation. These findings implicate that health care professionals should inform gynaecological cancer patients that incontinence is a potential side effect, thus reducing the information gap between expectations and reality. It also seems important to evaluate whether PFMT is as effective for GCS as for women in general.

Acknowledgments The study was funded by grants from the Swedish Cancer Society, The Kamprad Family Foundation for Entrepreneurship, Research and Charity, Linköping University, Region Östergötland and FORSS (The Research Council of Southeast Sweden). We would like to thank all the gynaecological cancer survivors who participated in this study and Dr. Karin Bergmark and R.N. Lisen Heden for help with the recruitment of the study participants. We also want to thank Professor Gunnar Steineck and Dr. Karin Bergmark for their valuable advices and comments on the study design and methodology. Finally, we would like to thank Mr. A. Nygren, B.A., for his skilful linguistic revision.

\section{Appendix}

Interview guide

1. Can you tell us about how incontinence affects your life in general, for example, in what is usually called quality of life?

(a) How would it affect your quality of life if the incontinence decreased or you became completely recovered from incontinence? 
2. How do you see your opportunities to be active in daily life in general in view of the incontinence?

\section{(a) Daily chores}

(b) Socialising

(c) Recreational activities

(d) Physical training

(e) If incontinence decreased or you became completely restored from incontinence, how would that affect the extent to which you are physically active?

3. Can you tell us about your experience to train the pelvic floor muscles after your illness (if you have any experience of it)?

4. Can you tell us about your perceptions about pelvic floor muscle training?

The following are suggestions for follow-up questions to get the respondent to talk more:

1. Can you expand on this a bit more?

2. In what way?

3. What do/did you feel?

4. What do you mean?

The interviewer finally summarises all the questions and asks the respondent if she wants to add anything further.

Open Access This article is distributed under the terms of the Creative Commons Attribution-NonCommercial 4.0 International License (http:// creativecommons.org/licenses/by-nc/4.0/), which permits any noncommercial use, distribution, and reproduction in any medium, provided you give appropriate credit to the original author(s) and the source, provide a link to the Creative Commons license, and indicate if changes were made.

\section{References}

1. Ferlay J, Steliarova-Foucher E, Lortet-Tieulent J, Rosso S, Coebergh JW, Comber H, Forman D, Bray F (2013) Cancer incidence and mortality patterns in Europe: estimates for 40 countries in 2012. Eur J Cancer (Oxford, England: 1990) 49(6):1374-1403. doi:10.1016/j.ejca.2012.12.027

2. Lind H, Waldenstrom AC, Dunberger G, al-Abany M, Alevronta E, Johansson KA, Olsson C, Nyberg T, Wilderang U, Steineck G, Avall-Lundqvist E (2011) Late symptoms in long-term gynaecological cancer survivors after radiation therapy: a population-based cohort study. Br J Cancer 105(6):737-745. doi:10.1038/bjc. 2011.315

3. Dunbrger G (2010) Self-reported fecal incontinence and quality of life among gynecological cancer survivors [dissertation]. 2010-0528, Department of Oncology-Pathology, - Karolinska Institutet

4. Waldenström A-CA (2013) Towards eliminating pelvic bone pain after radiation therapy among long-term gynecological cancer survivors [dissertation]. 2013, Department of Oncology Sahlgrenska Academy at University of Gothenburg
5. Klint A, Tryggvadottir L, Bray F, Gislum M, Hakulinen T, Storm HH, Engholm G (2010) Trends in the survival of patients diagnosed with cancer in female genital organs in the Nordic countries 19642003 followed up to the end of 2006. Acta Oncol (Stockholm, Sweden) 49(5):632-643. doi:10.3109/02841861003691945

6. Norton C, Whitehead WE, Bliss DZ, Harari D, Lang J (2010) Management of fecal incontinence in adults. Neurourol Urodyn 29(1):199-206. doi:10.1002/nau.20803

7. Abrams P, Andersson KE, Birder L, Brubaker L, Cardozo L, Chapple C, Cottenden A, Davila W, de Ridder D, Dmochowski R, Drake M, Dubeau C, Fry C, Hanno P, Smith JH, Herschorn S, Hosker G, Kelleher C, Koelbl H, Khoury S, Madoff R, Milsom I, Moore K, Newman D, Nitti V, Norton C, Nygaard I, Payne C, Smith A, Staskin D, Tekgul S, Thuroff J, Tubaro A, Vodusek D, Wein A, Wyndaele JJ (2010) Fourth international consultation on incontinence recommendations of the international scientific committee: evaluation and treatment of urinary incontinence, pelvic organ prolapse, and fecal incontinence. Neurourol Urodyn 29(1): 213-240. doi:10.1002/nau.20870

8. Monz B, Pons ME, Hampel C, Hunskaar S, Quail D, Samsioe G, Sykes D, Wagg A, Papanicolaou S (2005) Patient-reported impact of urinary incontinence - results from treatment seeking women in 14 European countries. Maturitas 52(Suppl 2):S24-S34. doi:10.1016/j.maturitas.2005.09.005

9. Peterson JA (2008) Minimize urinary incontinence: maximize physical activity in women. Urol Nurs 28(5):351-356

10. Hagglund D, Walker-Engstrom ML, Larsson G, Leppert J (2001) Quality of life and seeking help in women with urinary incontinence. Acta Obstet Gynecol Scand 80(11):1051-1055

11. O'Conor RM, Johannesson M, Hass SL, Kobelt-Nguyen G (1998) Urge incontinence. Quality of life and patients' valuation of symptom reduction. Pharmacoeconomics 14(5):531-539

12. Dumoulin C, Hay-Smith EJ, Mac Habee-Seguin G (2014) Pelvic floor muscle training versus no treatment, or inactive control treatments, for urinary incontinence in women. Cochrane Database Syst Rev 5:Cd005654. doi:10.1002/14651858.CD005654.pub3

13. Norton C, Cody JD (2012) Biofeedback and/or sphincter exercises for the treatment of faecal incontinence in adults. Cochrane Database Syst Rev 7:Cd002111. doi:10.1002/14651858.CD002111.pub3

14. Rutledge TL, Rogers R, Lee SJ, Muller CY (2014) A pilot randomized control trial to evaluate pelvic floor muscle training for urinary incontinence among gynecologic cancer survivors. Gynecol Oncol 132(1):154-158. doi:10.1016/j.ygyno.2013.10.024

15. Olsen JA, Smith RD (2001) Theory versus practice: a review of 'willingness-to-pay' in health and health care. Health Econ 10(1): $39-52$

16. Ryan F, Coughlan M, Cronin P (2009) Interviewing in qualitative research: the one-to-one interview. International journal of therapy and. Rehabilitation 16(6):309-314

17. Krippendorff K (2013) Content analysis: an introduction to its methodology. SAGE, Thousand Oaks, Calif

18. Dunberger G, Lind H, Steineck G, Waldenstrom AC, Nyberg T, AlAbany M, Nyberg U, Vall-Lundqvist E (2010) Self-reported symptoms of faecal incontinence among long-term gynaecological cancer survivors and population-based controls. Eur J Cancer (Oxford, England: 1990) 46(3):606-615. doi:10.1016/j.ejca.2009.10.023

19. Development of the WHOQOL: rationale and current status (1994). M. E. Sharpe

20. Ketabi Z, Moller LM, Lose G (2007) Self reported quality of life among patients referred to a gynaecologic ward with urinary incontinence. Ugeskr Laeger 169(11):1019-1022

21. Dunberger G, Lind H, Steineck G, Waldenstrom AC, Nyberg T, al-Abany M, Nyberg U, Avall-Lundqvist E (2010) Fecal incontinence affecting quality of life and social functioning among long-term gynecological cancer survivors. Int J Gynecol 
Cancer: Off J Int Gynecol Cancer Soc 20(3):449-460. doi:10.1111/IGC.0b013e3181d373bf

22. Penson RT, Wenzel LB, Vergote I, Cella D (2006) Quality of life considerations in gynecologic cancer. FIGO 26th Annual Report on the Results of Treatment in Gynecological Cancer. Int J Gynaecol Obstet: Off Organ Int Fed Gynaecol Obstet 95(Suppl 1):S247-S257. doi:10.1016/s0020-7292(06)60040-4

23. Andersson G, Johansson JE, Nilsson K, Sahlberg-Blom E (2008) Accepting and adjusting: older women's experiences of living with urinary incontinence. Urol Nurs 28(2):115-121
24. Anders K (2000) Coping strategies for women with urinary incontinence. Bailliere Best Pract Res Clin Obstet Gynaecol 14(2):355-361

25. Olsen JA, Donaldson C, Shackley P (2005) Implicit versus explicit ranking: on inferring ordinal preferences for health care programmes based on differences in willingness-to-pay. J Health Econ 24(5):990-996. doi:10.1016/j.jhealeco.2005.04.001

26. Calman KC (1984) Quality of life in cancer patients - an hypothesis. J Med Ethics 10(3):124-127

27. Polit DF, Beck CT (2008) Nursing research: generating and assessing evidence for nursing practice. Lippincott Williams \& Wilkins 